\title{
AVALIAÇÃO DAS PERDAS DE MANGA (Mangifera indica L.) NO MERCADO VAREJISTA DA CIDADE DE BOTUCATU-SP ${ }^{1}$
}

\author{
JOSÉ MATHEUS YALENTI PEROSA ${ }^{2}$, CÍNTIA DE SOUZA SILVA ${ }^{3}$, CIBELE RIBEIRO ARNALDI $^{4}$
}

RESUMO-O elevado percentual de perdas na comercialização de manga no Brasil faz com que apenas parcela da produção chegue à mesa do consumidor. $\mathrm{O}$ presente trabalho determinou, em equipamentos de varejo da cidade de Botucatu - SP, as perdas de manga, suas causas e emitir sugestões para a redução das mesmas. Foram selecionados 22 equipamentos entre supermercados, quitanda/sacolões e feiras livres. O volume estimado de manga comercializada neste município foi 114 t/ano. Verificaram-se as seguintes perdas médias por variedade de manga: 11,5\% para 'Tommy Atkins', 12,4\% para 'Haden' e 12,7\% para as outras variedades. O valor total anual destas perdas no comércio varejista da cidade, em 2007, atingiu R \$ 49.200,00 (US\$25.231,00), correspondente a 14 toneladas. Os percentuais médios de perda mostram grande semelhança quando comparados a estudos realizados em outras localidades. Os resultados obtidos apontam para a necessidade de melhor gestão de estoques, de exposição da fruta para o consumidor e uso de tecnologia no transporte e armazenagem para a manutenção da qualidade e redução das perdas. Conclui-se também pela necessidade de maiores investimentos em capacitação técnica dos encarregados do setor de frutas e hortaliças.

Termos de indexação: Manga, Mangifera indica, perdas, comercialização.

\section{MANGO LOSS ESTIMATE IN RETAIL MARKET}

ABSTRACT - Losses in the mango commercialization process in Brazil has reduced its offer to the consumer. The present study aims at determining these losses in different purchase sites of the retail market, its causes and suggestions for reducing them. Twenty two retail points, including supermarkets, greengroceries and free fair were selected in Botucatu, state of São Paulo, Brazil. The total amount commercialized was 114 ton/year. The following average losses were verified for each mango variety: 'Tommy Atkins' (11, 5\%), Haden $(12,4 \%)$ and $12,7 \%$ for other varieties. The total loss in retail market reached US\$ 25.231 , 00 corresponding to 14 tons. The average loss percentage observed is compatible with previous studies running in other cities. The results suggest the need of better management, the exposure of the fruit to the consumer, technology in the transportation of the fruits and most appropriate storage for maintaining the quality and the reduction of losses. The results show the need of higher investment in technical personnel reskilling in fruit and vegetable sector.

Index Terms: mango, Mangifera indica, losses, commercialization.

\section{INTRODUÇÃO}

O agronegócio é responsável por 33\% do Produto Interno Bruto, $42 \%$ das exportações totais e $37 \%$ dos empregos no Brasil. O segmento de frutas constitui importante parcela do agronegócio nacional, com destacado potencial em termos de geração de empregos, renda e divisas. O Brasil é o terceiro polo mundial de fruticultura, com uma produção anual de cerca de 38 milhões de toneladas. Desse total, o mercado interno absorve aproximadamente $55 \%$, e as exportações são responsáveis pelos restantes $45 \%$ (MAPA, 2005). Na cultura da manga, a participação do mercado externo em 2007 foi de $9 \%$ do total produzido (ALICE-MDICE/IBGE). Destacam-se a cultura da laranja, com produção de 17,8 milhões de toneladas, banana (7 milhões), uva (1,2 milhão), maçã (850 mil) e manga (850 mil).

Inúmeros fatores têm dificultado uma coordenação eficiente ao longo das cadeias produtivas, ocasionando falta de confiança entre as partes envolvidas, custos elevados e perda de qualidade durante o processo, restringindo o planejamento e ocasionando perdas do produto, com implicações no consumo (Gutierrez, 2002).

A manga é um dos produtos em que a questão da coordenação ao longo da cadeia é relevante. A fruta é cultivada em área de aproximadamente

\footnotetext{
${ }^{1}$ (Trabalho 196-08). Recebido em: 25-07-2008. Aceito para publicação em: 03-04-2009.

${ }^{2}$ Depto. de Gestão e Tecnologia Agroindustrial - Fac. de Ciências Agronômicas - Campus de Botucatu - UNESP - Faz. Exp. Lageado C. P. 237 - 18603-970 - Botucatu - SP e-mail: dede@fca.unesp.br.

${ }^{3}$ Fac. de Ciências Agronômicas - Campus de Botucatu - UNESP - Faz. Exp. Lageado - C.P. 237 - 18603-970 - Botucatu - SP. e-mail: pokaropa@zipmail.com.br;

${ }^{4}$ Programa SAI/Sebrae- Modulo Botucatu - Incubadora de Empresas de Base Tecnológica - Faz. Exp. Lageado - C.P. 237 18603-970 - Botucatu - SP - e-mail: cibelearnaldi@uol.com.br
} 
70 mil ha, sendo os estados da Bahia, São Paulo e Pernambuco responsáveis por $75 \%$ da produção em 2005. O Estado de São Paulo responde por aproximadamente $25 \%$ do total produzido no Brasil, e a manga é considerada a fruta de maior potencial para exportação em curto prazo (Lucafó e Boteon, 2002). A exportação passou de 105 mil toneladas em 2004, para 133 mil toneladas em 2008, crescimento de $26,7 \%$ no período, sendo os Países Baixos o principal destino ${ }^{1}$. Sua produção tem-se expandido e constitui hoje importante alternativa para a agricultura familiar e para a grande produção.

No Brasil, existem mais de 300 variedades de manga, sendo que as mais cultivadas são de origem norte-americana, como a 'Tommy Atkins', 'Haden', 'Keitt', 'Van Dyke', 'Parvin' e 'Winter', entre outras (Pizzol et al., 1998). Segundo Frutiséries (1998), no período de 1993-97, observou-se aumento substancial no volume comercializado da 'Tommy Atkins' (cerca de $170 \%)$, da 'Haden' (39,4\%) e da 'Keitt' (414\%).

Estudos sobre a comercialização de frutas mostram volumes de perdas expressivos. Segundo Frutifatos (1999), o percentual de perdas em diferentes etapas do processo de comercialização é bastante elevado: $2 \%$ na estocagem, $10 \%$ no transporte e $83 \%$ na exposição do produto na loja.

Também na comercialização de manga se observa elevado índice de perdas, fazendo com que apenas parcela da produção chegue à mesa do consumidor. As perdas físicas representam perdas econômicas, que são repassadas ao preço, comprometendo o consumo desta fruta em relação a concorrentes e afetando a competitividade de toda a cadeia produtiva $^{2}$. Ueno (1976) avaliou em 19\% a perda média na comercialização de manga na cidade de São Paulo, mais elevada em quitandas, seguida dos supermercados e da feira livre. Já Tsunechiro et al. (1994), por meio de pesquisa semelhante, estimaram perda média de $12,6 \%$, sendo também maior nas quitandas e menor nas feiras livres.

Pesquisas sobre perdas físicas e econômicas em diferentes etapas da comercialização são importantes para a implementação de políticas públicas e privadas visando ao desenvolvimento do setor e à competitividade da cadeia. Embora as causas das perdas não estejam associadas unicamente ao varejo, a determinação das mesmas nessa etapa da comercialização pode oferecer subsídios aos agentes da cadeia agroalimentar da manga, direcionando-os para ações que melhorem o sistema de comercialização desta fruta.
Este trabalho teve por objetivo central avaliar as perdas de diferentes variedades de manga no varejo da cidade de Botucatu - SP, no ano de 2007.

Os objetivos especificos são:

avaliação das perdas físicas em diferentes equipamentos de varejo;

avaliação das perdas econômicas;

levantamento dos fatores de perdas nos equipamentos de varejo;

levantamento e análise de sugestões do varejo para a redução das perdas.

\section{MATERIAL E MÉTODOS}

A pesquisa de campo teve por objetivo avaliar as perdas de manga no processo de comercialização. O termo avaliação constitui uma aproximação das perdas dos alimentos, contrapondo-se à medição, que é um processo mais preciso e objetivo. O uso desse termo tem implícito, portanto, um grau de subjetividade decorrente da dificuldade de obtenção de informações mais precisas (National Academy of Sciences, 1982). O conceito de perda, neste trabalho, baseia-se em Carvalho (1992), que o define como reduções na quantidade física do produto disponível para consumo, que podem vir acompanhadas por uma redução na qualidade, diminuindo o valor comercial ou nutritivo do produto.

Foram consideradas na pesquisa as variedades mais encontradas no varejo da cidade: 'Tommy Atkins', 'Haden' e outras ('Palmer', 'Espada', 'Coquinho' e 'Rosa'). A avaliação das perdas foi realizada mediante levantamento junto a três tipos de equipamentos varejistas (supermercado, quitanda/ sacolão e feira livre), responsáveis pela quase totalidade dos abastecimentos de gêneros hortícolas da cidade de Botucatu.

Foram pesquisados 22 equipamentos (11 supermercados, 8 quitandas/sacolões e 3 feirantes). Para a determinação do número de equipamentos a ser pesquisado, procedeu-se a um levantamento do número de equipamentos nos diferentes bairros da cidade. De acordo com estudos de varejo já realizados na cidade de Botucatu, os equipamentos selecionados são, majoritariamente, representativos na comercialização de hortifrutícolas (Silva, 2003).

O levantamento de dados foi realizado mediante aplicação de questionário, diretamente com os encarregados do setor de hortifrutícolas, no caso de supermercados, e com os proprietários de quitanda/

\footnotetext{
${ }^{1}$ Agrianual 2008.

${ }^{2}$ De acordo o pesquisador Mohammad Menhazuddin Choudhury, da Embrapa Semiárido, a variação de perdas oscila entre 20 e $40 \%$, reduzindo as margens de ganhos econômicos e comprometendo o negócio dessa fruta. http://www.cpatsa.embrapa.br/noticias/noticia68.htm. Acesso em 26-03-2007
} 
sacolão e feirantes.

Para a avaliação das perdas no varejo, foram utilizados os seguintes dados e informações:

Volume mensal comercializado de cada variedade de manga nos dois principais atacadistas de hortifrutícolas da cidade de Botucatu, responsáveis pela distribuição de manga e o seu destino junto aos diferentes equipamentos varejistas. Esses dados foram levantados através da aplicação de questionário.

Perda física (médias ponderadas por equipamento de varejo). Os dados foram coletados no mês de agosto de 2007, período de entressafra da comercialização dessa fruta. A estimativa de perda teve como referência o mês de coleta. Assim, as porcentagens de perdas verificadas no mês de agosto foram multiplicadas pela quantidade comercializada no ano. Supondo que as perdas devam ser maiores no período da safra, os dados de perdas físicas coletados devem estar subestimados.

Preço: preço médio de venda no mês de agosto de 2007, sendo utilizado um fator de correção referente à participação do mês na média anual. Dada a variação estacional de preços, utilizou-se uma média ponderada dos preços no ano, tendo como fator de ponderação a quantidade comercializada em cada mês. Para essa correção, foram usados os preços médios mensais da manga comercializada na Companhia de Entrepostos e Armazéns Gerais de São Paulo - CEAGESP, no período de 2002 a 2006.

\section{RESULTADOS E DISCUSSÃO}

Do total de manga comercializado no varejo da cidade de Botucatu-SP, a variedade 'Tommy Atkins' teve a participação de 37\%, a 'Haden' 7,3\%, e outras variedades, como a 'Palmer', 'Espada', 'Coquinho' e 'Rosa', 56,7\%. A participação da variedade 'Tommy Atkins' no total comercializado é menor que a verificada na central atacadista da CEAGESP ${ }^{3}$.

Os supermercados são responsáveis por $50 \%$ do total comercializado, seguidos da quitanda/sacolão e feira livre, com $25 \%$ cada um. Estudos mostram que os supermercados apresentam atributos valorizados pelos consumidores, como horário de atendimento, higiene e limpeza, facilidade de pagamento, atendimento e forma de exposição dos produtos (Frutifatos, 2003). O segundo lugar de preferência são os sacolões, devido principalmente ao preço, proximidade, variedade de produtos, ofertas e promoções. A feira livre vem perdendo espaço gradativamente, aparecendo como terceiro local mais qualificado, sendo a aparência dos produtos e os preços as vantagens que mais atraem o consumidor. A feira tem reduzido sua participação no varejo, não por ser ineficiente, mas porque os supermercados evoluíram e agregaram vantagens ao consumidor (Panorama Rural, 2001).

A quantidade de manga comercializada foi estimada em 114 t/ano (9,5 t/mês). A quantidade total e por variedade é mostrada na Tabela 1. A estimativa do consumo per capita na cidade foi de 0,94 $\mathrm{kg} / \mathrm{ano}^{4}$, abaixo do valor encontrado para a média nacional, de aproximadamente 1,2 kg/ano (Queiroz Pinto, 2002).

Na Tabela 1, também são mostradas as perdas verificadas por variedade e total. A perda média foi de $12,8 \%$ do volume comercializado, sendo $12,2 \%$ na variedade 'Tommy Atkins', $12,9 \%$ na 'Haden' e $13,2 \%$ para outras variedades.

O percentual de perda por equipamento mostra que as menores perdas ocorrem em supermercados (10,5\%), seguidos das feiras livres (13,3\%) e quitandas/sacolões $(14,5 \%)$. Tais resultados são semelhantes aos descritos por Silva et al. (2003) na comercialização da banana. Quando comparado a estudo realizado na cidade de São Paulo (Tsunechiro et al, 1994), observa-se menor perda nos supermercados (14,2\% em São Paulo e 10,5\% em Botucatu), e perda maior nas feiras livres (10,4\% em São Paulo e 13,3\% em Botucatu). O valor total das perdas estimadas no ano de 2007 foi de $\mathrm{R} \$ 49.200,00$, sendo que $\mathrm{R} \$ 21.120,00$ referem-se aos supermercados, $\mathrm{R} \$ 14.747,00$ às quitandas/sacolões e $\mathrm{R} \$ 13.334,00$ às feiras livres.

Na Tabela 2, são apresentados diferentes fatores relacionados a perdas nos equipamentos de varejo pesquisado: forma de exposição, frequência de compra, tipo de embalagem e forma de comercialização.

A menor quantidade de perda nos supermercados pode ser atribuída a diferentes fatores. Os supermercados dispõem de boa infraestrutura física para operar com hortifrutícolas e, na área de gestão, tem aprimorado suas estratégias de compra, passando a exigir de seus fornecedores mercadorias de melhor qualidade, podendo reduzir seus níveis de perdas. Sesso Filho (1999) cita ainda que a qualificação dos fornecedores aumenta o poder de negociação da empresa supermercadista, que acaba garantindo melhores desempenhos quando comparadas a outros varejistas. Outra medida que deve ter contribuído para os supermercados apresentarem menores índices de perda foi a utilização

\footnotetext{
${ }^{3}$ Agrianual 2008

${ }^{4} \mathrm{O}$ consumo per capita na cidade de Botucatu foi calculado a partir da população estimada pelo IBGE em 2006, de 121.274 habitantes, o que daria um consumo de aproximadamente 114 toneladas/ano.
} 
de gôndolas refrigeradas, como mostrado na Tabela 2. Segundo Hortifruti Brasil (2002), o não uso das câmaras frigoríficas constitui um dos prováveis agravantes das perdas.

O mesmo ocorre quando o fator é a frequência de compra: embora a maioria dos equipamentos realizem suas compras de 1 a 3 vezes na semana (mais de $60 \%), 18,2 \%$ dos supermercados o fazem diariamente, procedimento que pode estar contribuindo para as menores perdas verificadas nesse equipamento.

A Tabela 2 mostra que $13,7 \%$ dos supermercados utilizam embalagens de papelão, enquanto quitandas/sacolões e feiras livres preferem embalagens de madeira $(93,7 \%$ e $100 \%$, respectivamente). Atualmente, recomenda-se o uso de caixas de papelão ondulado, que protegem o produto contra choques mecânicos, suportam ambientes úmidos e é o material mais indicado para paletização. Há uma diferença das perdas médias entre os supermercados que utilizam embalagens de papelão $(9,5 \%)$, dos supermercados que utilizam caixas de madeira $(11 \%)$, corroborando as indicações dos estudos citados para o uso de embalagem de papelão.

As perdas verificadas nas quitandas/sacolões foram as mais acentuadas. Segundo Silva et al. (2003), a exposição em sacolões é feita em espaços relativamente amplos, com grande variedade de produtos, dificultando o controle da manipulação pelos clientes e o controle de estoques.

\section{Principais causas de perdas e sua relação com os diferentes equipamentos de varejo}

A Tabela 3 mostra as principais causas de perdas segundo a percepção dos varejistas, enquanto na Tabela 4 são indicadas sugestões para a redução das mesmas.

A principal causa das perdas apontada na pesquisa foi a manipulação excessiva dos clientes (26,5\%), resultado também encontrado em Tsunechiro et al. (1994), Frutifatos (1999) e Silva et al. (2003). Os dados mostram ainda que esse fator é importante nos diferentes equipamentos: $27,3 \%$ em supermercados, $26,3 \%$ em quitandas/sacolões e $25,0 \%$ em feiras livres, evidenciando a dificuldade no controle pontual junto aos consumidores. Essa preocupação dos varejistas é indicada pela manifestação na Tabela 4, onde 19,9\% dos entrevistados sugerem a conscientização do cliente como fator importante de redução de perdas.

Outro fator apontado como indutor de perdas foi o excedente de oferta (17,3\%). Este dado revela pouca eficiência no controle de estoques por estes equipamentos, uma vez que o excedente de oferta está relacionado com a gestão deficiente de compras.
Os dados da Tabela 3 mostram a importância deste fator nos diferentes equipamentos de varejo: $18,4 \%$ em supermercados, $15,8 \%$ em quitandas/sacolões e $16,7 \%$ em feiras livres. Contudo, quando se verifica a Tabela 4 , somente $7,5 \%$ descrevem o controle de estoques como redutor de perdas, sendo os supermercadistas os únicos a citar tal sugestão.

O fator "más condições de transporte" também aparece como grande causador de perdas na Tabela 3. Segundo a Frutifatos (2002), o transporte adequado da manga é realizado em caminhões refrigerados ou protegidos contra o vento, com as frutas embaladas e nunca a granel. Tais procedimentos são importantes para evitar manchas na casca, manter uma aparência bonita, consistência firme e suculência da fruta. Na etapa de distribuição até o varejo da cidade de Botucatu, esse tipo de transporte é praticamente inexistente.

Na Tabela 3, também se descreve o armazenamento inadequado como causador de perdas em $14,5 \%$ dos varejistas. De acordo com Frutifatos (2002), o armazenamento ideal da manga ocorre a $13^{\circ} \mathrm{C}$ e a umidade relativa do ar entre $85-90 \%$, quando a fruta mantém suas qualidades ideais, aparência, maciez, suculência e consistência firme, por um maior período de tempo. Na Tabela 4, é mostrado que, para $11,9 \%$ dos varejistas, o armazenamento refrigerado é sugerido para diminuir as perdas de manga, assim como a compra da fruta de melhor qualidade. 
TABELA 1 - Volume comercializado ${ }^{1}$, quantidade e valor das perdas de mangas na cidade de BotucatuSP

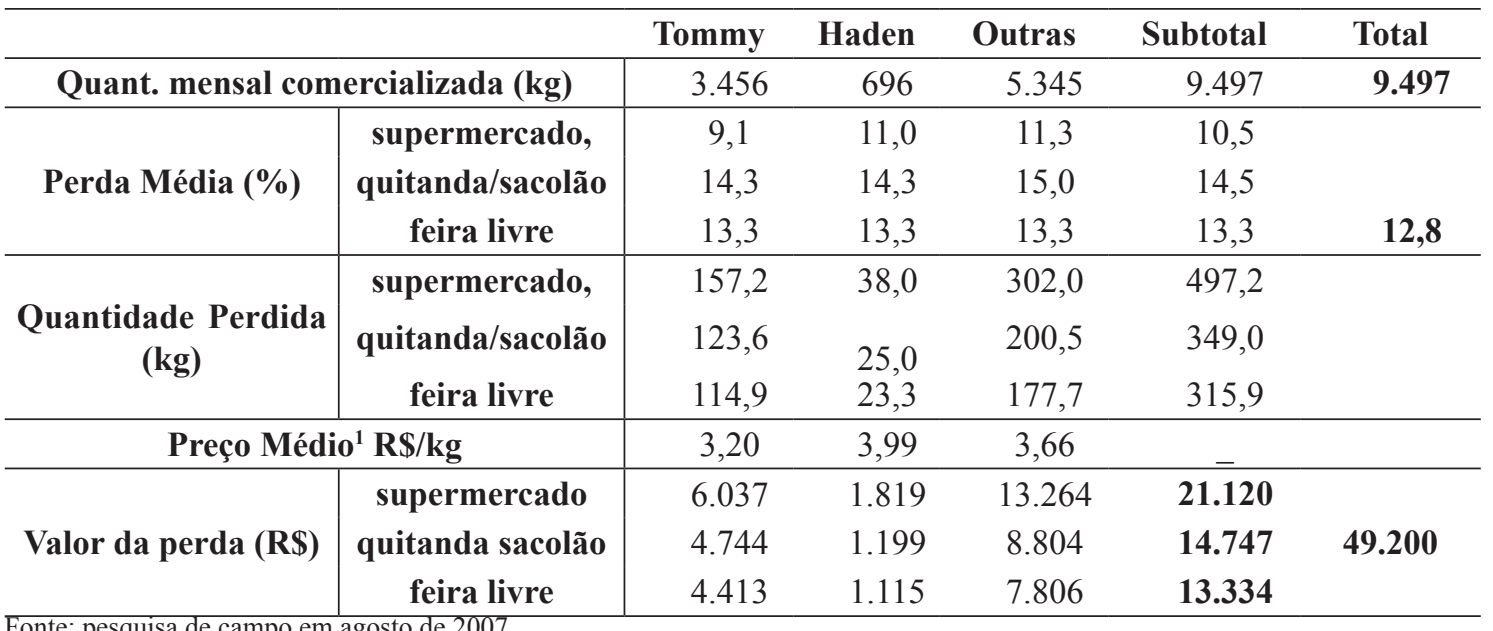

Fonte: pesquisa de campo em agosto de 2007

${ }^{1}$ Volume corrigido através de fator de correção referente à participação do mês da coleta no ano. (Fonte: Agrianual, 2008)

TABELA 2 - Forma de exposição, frequência de compra, tipo de embalagem e forma de comercialização de manga pelos equipamentos varejistas da cidade de Botucatu-SP.

\begin{tabular}{|c|c|c|c|c|}
\hline Equipamento & $\begin{array}{l}\text { Forma de } \\
\text { exposicão }\end{array}$ & $\begin{array}{c}\text { Frequência de } \\
\text { compras }\end{array}$ & $\begin{array}{c}\text { Tipo de } \\
\text { embalagem }\end{array}$ & $\begin{array}{c}\text { Forma de } \\
\text { comercializacão }\end{array}$ \\
\hline \multirow[b]{2}{*}{ Supermercado } & $\begin{array}{l}4,5 \% \text { gôndolas } \\
\text { refrigeradas }\end{array}$ & $\begin{array}{c}\text { 18,2\% diariamente } \\
63,6 \% \text { 1 a } 3 \text { vezes/ } \\
\text { semana }\end{array}$ & $\begin{array}{c}81,8 \% \text { madeira } \\
4,5 \% \text { plástico }\end{array}$ & $90,9 \%$ a granel \\
\hline & $\begin{array}{l}\text { 95,5\% gôndolas } \\
\text { a } \mathrm{T}^{\mathrm{o}} \text { ambiente }\end{array}$ & $\begin{array}{c}9,1 \% 4 \text { a } 6 \text { vezes/ } \\
\text { semana } \\
9,1 \% \text { outros }\end{array}$ & $13,7 \%$ papelão & $6,3 \%$ embalada \\
\hline Quitanda/sacolão & $\begin{array}{c}100 \% \text { gôndolas a } \\
\mathrm{T}^{\mathrm{o}} \text { ambiente }\end{array}$ & $\begin{array}{c}100 \% 1 \text { a } 3 \text { vezes/ } \\
\text { semana }\end{array}$ & $\begin{array}{c}93,7 \% \text { madeira } \\
6,3 \% \text { plástico }\end{array}$ & $100,0 \%$ a granel \\
\hline Feira livre & $\begin{array}{c}100 \% \text { gôndolas a } \\
\mathrm{T}^{\mathrm{0}} \text { ambiente }\end{array}$ & $\begin{array}{c}66,7 \% 1 \text { a } 3 \text { vezes } / \\
\text { semana } \\
33.3 \% \text { outros }\end{array}$ & $100,0 \%$ madeira & $100,0 \%$ a granel \\
\hline
\end{tabular}

Fonte: pesquisa de campo em agosto de 2007

TABELA 3 - Principais causas de perdas de manga, segundo a visão dos responsáveis pelos equipamentos varejistas da cidade de Botucatu-SP.

\begin{tabular}{l|ccc|c}
\hline \multirow{2}{*}{ Motivo } & \multicolumn{3}{c}{ \% de respostas } & \multirow{2}{*}{ Média $^{{ }^{1}}$} \\
\cline { 2 - 4 } Manipulação excessiva do cliente & Supermercado & Quitanda/sacolão & Feira livre & \\
Excedente de oferta & 27,3 & 26,3 & 25,0 & 26,5 \\
Más condições de transporte & 18,4 & 15,8 & 16,7 & 17,3 \\
Armazenamento inadequado & 27,3 & 5,3 & 0,0 & 15 \\
Baixa qualidade da fruta & 9,0 & 31,6 & 8,3 & 14,5 \\
Fruta muito perecível & 9,0 & 15,8 & 8,3 & 10,5 \\
Preços elevados & 4,5 & 0,0 & 16,7 & 6,4 \\
Falta de padronização da fruta & 0,0 & 0,0 & 16,7 & 4,2 \\
Embalagens inadequadas & 4,5 & 0,0 & 0,0 & 2,3 \\
Forma de exposição da fruta & 0,0 & 0,0 & 8,3 & 2,1 \\
Ponderda pla & 0,0 & 5,2 & 0,0 & 1,3 \\
\hline
\end{tabular}

Ponderada pela participação do equipamento na venda de manga.

Fonte: pesquisa de campo em agosto de 2007 
TABELA 4 - Sugestões para a redução das perdas de manga pelos responsáveis dos equipamentos varejistas da Cidade de Botucatu-SP.

\begin{tabular}{lcccc}
\hline \multirow{2}{*}{ Sugestões } & \multicolumn{3}{c}{ \% de respostas } & \multirow{2}{*}{ Média $^{1}$} \\
\cline { 2 - 4 } Cuidados no transporte & Supermercado & $\begin{array}{c}\text { Quitanda/ } \\
\text { sacolão }\end{array}$ & Feira livre & \\
Conscientização do cliente & 15,0 & 35,3 & 40,0 & 26,3 \\
Armazenamento refrigerado & 15,0 & 29,4 & 20,0 & 19,9 \\
Compra de fruta com maior qualidade & 15,0 & 17,6 & 0,0 & 11,9 \\
Uso de embalagens plásticas & 20,0 & 5,9 & 0,0 & 11,5 \\
Controle de estoque & 10,0 & 0,0 & 20,0 & 10,0 \\
Compra da fruta menos madura & 15,0 & 0,0 & 0,0 & 7,5 \\
Reposição diária dos frutos & 15,0 & 0,0 & 0,0 & 7,5 \\
Treinamento de funcionários & 5,0 & 0,0 & 20,0 & 7,5 \\
Classificação dos frutos & 0,0 & 11,8 & 0,0 & 3,0 \\
Melhor exposição dos frutos & 5,0 & 0,0 & 0,0 & 2,5 \\
\hline
\end{tabular}

Ponderada pela participação do equipamento na venda de manga.

Fonte: pesquisa de campo em agosto de 2007

\section{CONCLUSÕES}

1-Dado o caráter aproximativo da avaliação das perdas nesse estudo, pode-se inferir que a comercialização de manga na cidade de Botucatu é feita predominantemente pelo setor supermercadista. Dado que o menor índice de perdas ocorre nesse equipamento, é de se esperar que o total de perdas de manga no varejo tenda a se reduzir.

2-De acordo com os responsáveis pelas compras no varejo, a qualidade da manga ofertada está diretamente relacionada com o padrão de qualidade da fruta adquirida. Embora não tenha sido analisada a qualidade da fruta adquirida pelos equipamentos pesquisados, as entrevistas realizadas com os responsáveis pelas compras, assim como a observação das frutas recém-expostas para venda, indicam que esse fator não deve ser relevante para o diferencial de perdas verificadas no varejo da cidade de Botucatu.

3-Outros fatores, como armazenagem e exposição da fruta, contribuem para redução da qualidade e consequente aumento das perdas. Nesse sentido, algumas ações como o uso de refrigeração e exposição/reposição mais adequada, são indicadas para a redução de perdas.

4-Recomendações: constatou-se que, em muitos casos, a fruta fica exposta por um período muito longo, contribuindo para o aumento das perdas. Gestão de compras vinculada ao comportamento do consumidor poderia contribuir para a redução das perdas. Procedimentos, como compras baseadas no consumo predeterminado, com uso de planilhas de vendas, pesquisa de mercado e estudos de sazonalidade de consumo, poderiam ser utilizados pelos equipamentos varejistas. Sugere-se a necessidade de maiores investimentos em capacitação técnica para os encarregados do setor de frutas e hortaliças. Por fim, frente à realidade encontrada na comercialização dessa fruta, futuros estudos relacionados ao comportamento do consumidor poderiam subsidiar outras ações adequadas ao segmento varejista.

\section{REFERÊNCIAS}

AGRIANUAL 2008: anuário da agricultura brasileira. São Paulo: Instituto FNP, 2007. 502p.

BRASIL. Ministério da Agricultura, Pecuária e Abastecimento - MAPA. Agronegócio Brasileiro: uma oportunidade de investimentos. 2005. Disponível em: $<$ http://www.agricultura.gov.br $>$. Acesso em: 16 mar. 2007.

CARVALHO, F.C. Perdas na comercialização de milho no Brasil e seus impactos sócioeconômicos. In: CONGRESSO NACIONAL DE MILHO E SORGO, 19., 1992, Porto Alegre. Conferências... p. 247-258. 
FRUTIFATOS: informação para a agricultura irrigada. Brasília: Ministério da Integração, 1999. v.1, $24 \mathrm{p}$.

FRUTIFATOS: informação para a agricultura irrigada. Brasília: Ministério da Integração, 2002. v.2, 64 p.

FRUTIFATOS: informação para a agricultura irrigada. Brasília: Ministério da Integração, 2003. v. 4, $48 \mathrm{p}$

FRUTISÉRIES. Manga Tommy Atkins. Brasília: Ministério da Integração, 1998. v. 2.

GUTIERREZ, A.S.D. O negócio de frutas frescas: novidades de mercados. 2002. Disponível em: <http://www.iea.sp.gov.br/OUT/verTexto. php?codTexto=563>. Acesso: 13 mar. 2007.

LUCAFÓ, B.H.S.; BOTEON, M. Potencial da manga brasileira no mercado internacional. In: CONGRESSO INTERNACIONAL DE ECONOMIA E GESTÃO DE AGRONEGÓCIOS, 3., 2001, Ribeirão Preto. Anais.... Ribeirão Preto: Universidade de São Paulo, Faculdade de Economia e Administração de Ribeirão Preto, 2001. 1 CD-ROM.

NATIONALACADEMY OF SCIENCES. Pérdidas de post-cosecha de alimentos en países en desarrollo. Viçosa: Centro Nacional de Treinamento em Armazenagem, 1982. 213 p. (Série CENTREINAR, 4).

PANORAMA RURAL. São Paulo: Agrishow (Abag, Abimaq, Anda e SRB). São Paulo: Ed. Publie Publicações e Eventos , 2001. n.30
PIZZOL, S. J.; FILHO MARTINES, J. G.; SILVA, T. H. S.; GONÇALVES, G.. O mercado da manga no Brasil: aspectos gerais. Preços Agrícolas, Piracicaba, v.12, n.131, p.34-35, 1998.

QUEIROZ PINTO, A.C. A produção, o consumo e a qualidade da manga no Brasil. Revista Brasileira de Fruticultura, Jaboticabal, v.24, n.3., p.597-796, 2002.

REVISTA HORTIFRUTI BRASIL. Piracicaba: CEPEA Escola Superior de Agricultura Luiz de Queiroz, v.1, n.5, p.1-13, 2002.

SESSO FILHO, U.A. Estratégias de comercialização de hortifrútis no setor supermercadista: estudo de casos. 1999. 80 f. Dissertação (Mestrado em Ciências)-Escola Superior de Agricultura "Luiz de Queiroz”, Universidade de São Paulo, Piracicaba, 1999.

SILVA, C.S.; PEROSA, J.M.Y.; RUA, P.S.; Abreu, C. L. M. de.; Pântano, S.C.; Vieira, C.R.Y.I.; Brizola, R.M. Avaliação econômica das perdas de banana no mercado varejista: um estudo de caso. Revista Brasileira de Fruticultura, Jaboticabal, v.25, n.2, p.229-234, 2003.

TSUNECHIRO, A.; UENO, L. H.; PONTARELLI, C. T. G. Avaliação econômica das perdas de hortaliças e frutas no mercado varejista da cidade de São Paulo, 1991/92. Agricultura em São Paulo, São Paulo, v. 41, n. 2, p. 1-15, 1994.

UENO, L. H. Perdas na comercialização de produtos hortifrutícolas na Cidade de São Paulo. Informações Agronômicas, São Paulo, v. 6, n. 3, p. 5-7, 1976. 